\title{
The Elpsa Framework for The Students' Spatial Reasoning Ability in Aceh
}

\author{
Nanda Rahmatul Wahidah ${ }^{1, a}$, Rahmah Johar ${ }^{1}$, and Cut Morina Zubainur ${ }^{1}$ \\ ${ }^{1}$ Department of Mathematics Education, Universitas Syiah Kuala, Banda Aceh, Indonesia \\ *Corresponding author: ${ }^{\text {a }}$ nandarw48@gmail.com | Phone Number: +6285260010898
}

\section{ARTICLE HISTORY}

Received : 20 March 2020

Revised : 29 March 2020

Accepted : 8 April 2020

\section{KEYWORDS}

ELPSA framework; Student Ability;

Spatial Reasoning;

\begin{abstract}
Geometry is one of the topics that students must comprehend in mathematics. However, in reality, the students' ability concerning geometry is relatively low due to their low spatial reasoning ability. The ELPSA framework is one of the solutions to develop students' spatial reasoning abilities. This study aimed to describe students' spatial reasoning ability and the impact on retention through the ELPSA framework. This research was part of the ELPSA framework research and development. The subjects were four students, chosen from 25 Grade 7 students from one of the junior high schools in Banda Aceh. They were selected based on the percentage of spatial reasoning aspects mastered. The instrument used was a semi-structured interview that was preceded by a written test. The results showed that the four subjects could manipulate objects in their mind to change the shape of D-3 to D-2. However, one of them could not determine its relation precisely. Three out of four subjects could imagine the appearance of an object from different perspectives. Besides, two out of four subjects could visualize objects to determine the number of unit cubes contained in the solid geometry and only one subject could imagine objects from various perspectives to determine the surface area but did not use the given measurement.
\end{abstract}

This is an open access article under the CC-BY-SA license.

\section{INTRODUCTION}

Geometry is one branch of mathematics taught at school, starting from elementary to higher education. In geometry, students learn about shapes, structures and analysing the characteristics and relationships of abstract objects. Therefore, spatial reasoning ability is one of the abilities that students must master to understand the concept (NCTM, 2000). Good spatial reasoning ability will make it easier for students to understand the relationships and properties of geometric objects.

Spatial reasoning ability is essential in various fields, such as Science, Technology, Engineering, and Mathematics (STEM) (Hegarty \& Waller, 2004). The ability aims to equip students with the skill to continue their education after schooling years either in work or college. In professional work, the spatial ability is widely used for people working in the field of architecture, cartoon designs, three-dimensional animated films, and so on (Subroto, 2016). In geometry, the ability of spatial reasoning can help students in visualising objects in two or three dimensions, understanding the relationship of their elements such as points, lines, or planes, so they can imagine the objects in mind.

Spatial reasoning ability is the ability that involves cognitive processes in representing and manipulating spatial objects as well as the relationships and transformations of their shapes (Clement and Battista, 1998). Spatial reasoning ability can help students understand concepts and solve geometry problems. Spatial reasoning ability includes the ability of visualisation and spatial orientation. Spatial visualisation ability is the ability to manipulate an object or model in the mind whether it is a change, the result of a transformation, and determine the position of an object. Spatial orientation is considered as a person's ability to imagine the appearance of an object from a different perspective.

Students' ability to solve geometry problems is still low (Sumarni \& Prayitno, 2016). This is because of the current mathematics curriculum in learning geometry does not provide sufficient opportunities for students to develop their spatial reasoning ability, so the students tend to memorise formulas without understanding the real meaning of solid geometry (Olkun, 2003). Therefore, it should be a concern of the teacher to carry out learning that is able to develop students' spatial reasoning ability.

One learning approach that can be applied to develop students' spatial reasoning ability is the ELPSA framework. The ELPSA framework is a learning framework developed based on constructivism and socialism. The components contain in this learning framework provide opportunities for students to develop ideas related to their personal experiences or prior knowledge, as well as engage in a discussion of mathematical ideas with others, so they obtain more meaningful learning (Lowrie \& Patahuddin, 2015).

ELPSA framework is a cyclic learning approach. The cycles of the ELPSA framework are Experience, Language, Pictorial, Symbol, and Application. Learning with this framework is a complex process where the five elements are interconnected and complementary. In the Experience phase, the activities carried 
out lead to how students use mathematics so far, the concepts known, how to obtain information, and the contribution of mathematics to students (inside and outside the classroom). In general, the Language component follows experience. It focuses on the language used to present mathematical ideas. Hence, the teacher needs to model the correct language, and students need to be encouraged to use clear language in describing their understanding to the teacher and their peers.

The use of concrete objects or models in learning is a Pictorial component of the ELPSA framework. The model is used for visual representation in presenting abstract ideas. This component can help students' understanding and provide stimulus to solve geometry problems. After assisting students to visualise abstract ideas at the Pictorial stage, students will then be involved in presenting, constructing, and manipulating information in the form of Symbols. In the last stage, Application, students are expected to be able to use their spatial reasoning ability in solving geometry problems (Lowrie \& Patahuddin, 2015).

The focus of this research is to examine the implementation of the developed media for students' spatial reasoning ability after the implementation of the ELPSA framework. Based on the description, the goal of this research is to describe the spatial reasoning ability of junior high school students through the ELPSA framework.

\section{RESEARCH METHOD}

This study was part of collaborative research involving three researchers. It was assisted by the Indonesian Realistic Mathematics Education and Research Center (P4MRI) Team at Syiah Kuala University (Unsyiah) to develop the ELPSA framework for developing students' spatial reasoning ability. Researchers participated as observers when the ELPSA framework was implemented. The school involved in this study was one of the junior high schools in Banda Aceh, which was a partner school of the Unsyiah P4MRI TEAM. The implementation of learning was carried out for six meetings attended by 33 students. At the last meeting of the learning process, students were given a post-test consisting of four questions. Based on the test results, four students were selected as research subjects based on the number of questions they solved. Subject 1 was able to answer all questions; subject 2 was able to answer three out of four questions, subject three was able to answer two out of four questions, and subject 4 was able to answer one out of four questions.

The research instrument used was a written test and a semi-structured interview. The written test was given to measure students' spatial reasoning abilities which consist of two aspects, namely visualisation and spatial orientation. Both aspects of spatial reasoning abilities were taken based on McGee's spatial ability indicators (Yilmaz, 2009). There were three spatial reasoning abilities questions developed in this study. Students are categorised to master the ability of visualization if they can draw three of the four patterns of cube nets, count the number of blocks in a solid geometry and the surface area of the cube. Students are said to fulfil the ability of spatial orientation if they are able to paint the front and side view of a cube-shaped box arrangement. These questions had been validated by three teachers and two mathematics education lecturers.

The semi-structured interview guide is used as a guide in conducting interviews with students with the theme of how students conduct spatial reasoning in solving problems after being taught through the ELPSA framework.

Data analysis techniques used in this study were based on the concept of Miles and Huberman (1992) who clarify data analysis in three steps, namely data reduction, data display, and conclusion drawing/verification). At the data reduction stage, the researcher summarised the interview results based on the recording. It was written in the form of an interview transcript so that it was easy to do the analysis. At this stage, the researcher also sorted out the data needed. In addition, researchers compared the results of interviews with the results of written tests and related them to the learning process based on the observations of researchers and supported by video recordings of learning. After being reduced, the data was presented in the form of narrative texts so that conclusions could be easily made. In the process of collecting data, the researchers also conducted time triangulation by interviewing the subject at different times to check the validity of the data.

\section{RESULTS AND DISCUSSION}

\subsection{Subject 1's Spatial Reasoning Abilities}

The spatial reasoning abilities of subject 1 can be seen from the subject's answers in Figure 1.

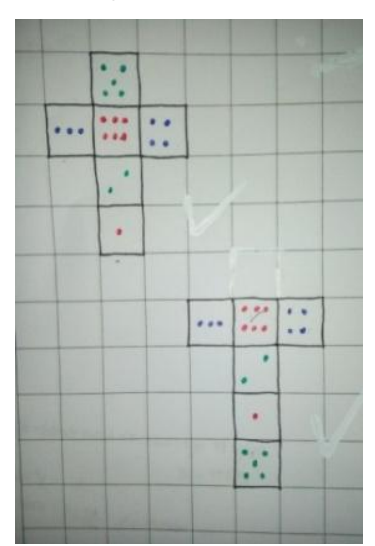

(a)

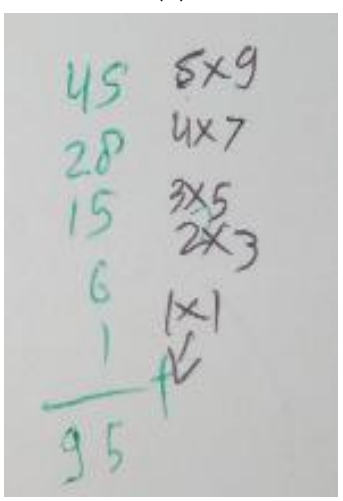

(c)

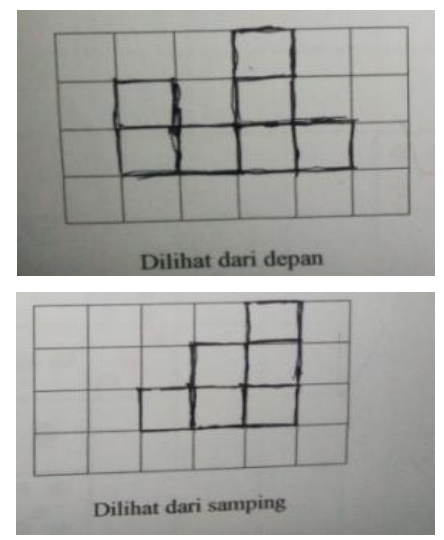

(b)

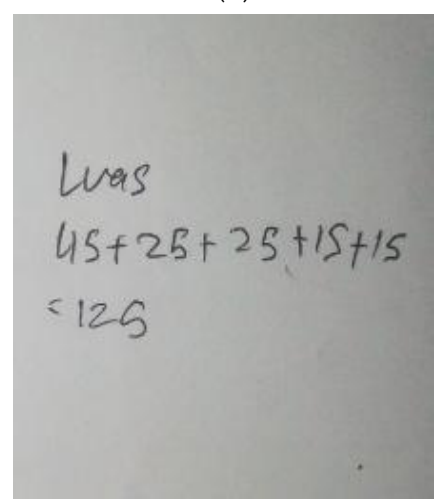

(d)
Figure 1. Subject 1's Answer to the Problem of Spatial Reasoning Ability

In Figure 1.a, it can be seen that the subject is able to paint two different net patterns with the $1-4-1$ pattern and determine the relation of the points on the opposite totalling seven-sides correctly. However, the subject did not describe cube nets with different patterns. Interviews were conducted to gather further information. The following are the results of 
the interview process.

PWPS $_{1}$ 1: "How many net patterns do you know besides what you have drawn?"

$\mathrm{SPS}_{1} 1$ : "Many, ma'am. Yet, I do not remember all."

PWPS $_{1} 1$ : "Do you think the pattern of the net you drew is a different pattern?"

$\mathrm{SPS}_{1} 1$ : "Yes ma'am."

PWPS $_{1} 1$ : "If I ask you to draw other nets, can you?"

SPS $_{1} 1 \quad$ : "Yes, I can. But not all of them."

PWPS $_{1} 1$ : "Please, try to draw them on this paper."

$\mathrm{SPS}_{1} 1$

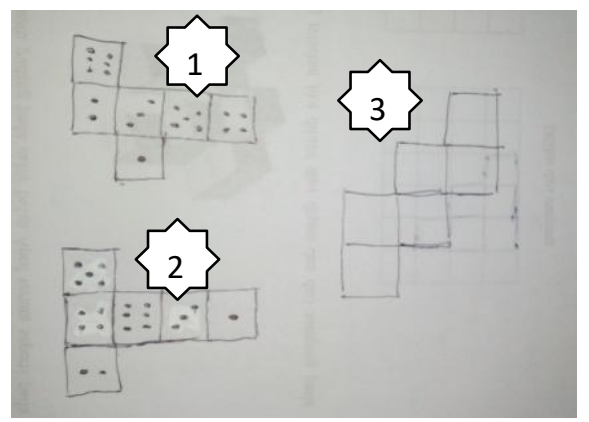

Figure 2. Subject 1's Confirmation Answer

PWPS $_{1} 1$ :" Do you think the nets 1 and 2 are the same or not?" SPS $_{1} 1$ :" Different ma'am. It is visible from the side position."

Based on the interview, it can be seen that the subject was able to paint cube nets with a 2-2-2 pattern, but could not distinguish the patterns of cube nets. Thus it can be concluded that subject 1 is able to visualize the change of three-dimensional objects into two-dimensional objects in painting the pattern of cube nets and determine the relation of points on the totalling seven-opposite sides. However, the subject was unable to distinguish the pattern of cube nets.

In addition, subject 1 was able to paint the arrangement of the cubes in two-dimensional shapes shown in Figure 1.b, determine the number of unit cubes in the given solid geometry shown in Figure 1.c, and determine the surface area by calculating the square unit that fills the surface of the solid geometry but did not use the given brick size. Thus, it can be concluded that subject 2 mastered most of the ability of spatial reasoning.

\subsection{Subject 2's Spatial Reasoning Ability}

The spatial reasoning abilities of subject 2 can be seen from the answers of the subjects in Figure 3

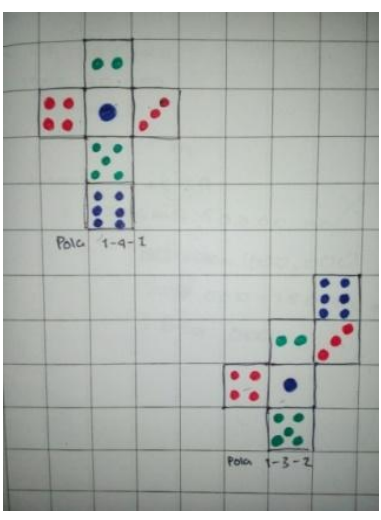

(a)
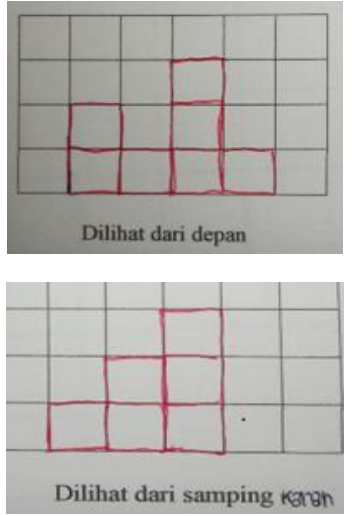

(b)
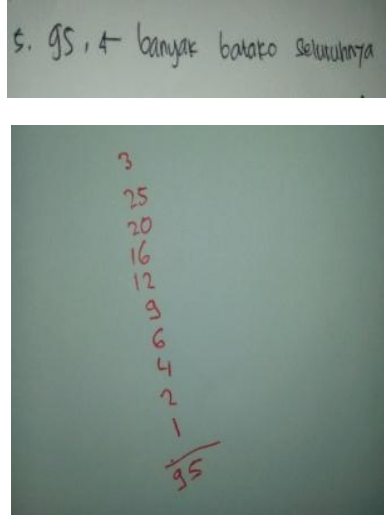

(c)

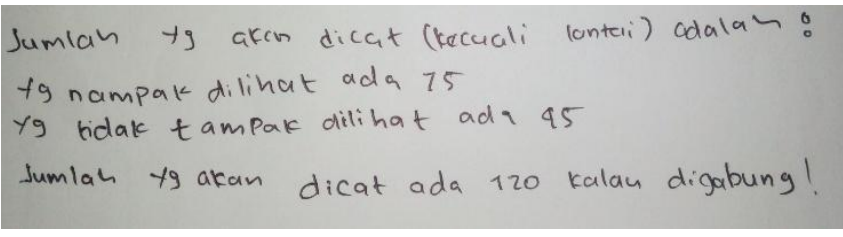

(d)

Figure 3. Subject 2 's Answers to the Problem of Spatial Reasoning Ability

It can be seen in Figure 3 that subject 2 was able to manipulate objects in mind in drawing different cube nets and determine the relation of the points on the totalling seven-opposite sides which is shown in Figure 3.a. There was a difference in the ability of subject 1 compared to subject 2 , for example, in drawing cube nets. Subject 2 was able to distinguish patterns of cube nets, as shown in Figure 3.a. This is consistent with the following interview excerpt.

$\mathrm{PWPS}_{2} 1$ : "If I ask you to draw cube nets, how many nets can you draw? Please draw on this paper"

$\mathrm{SPS}_{2} 1 \quad$ :

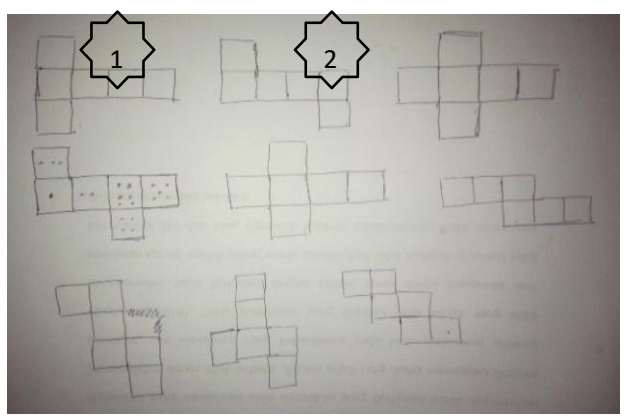

Fig 4 Subject 2's Confirmation Answer

PWPS $_{2} 1$ : "Do you think nets number 1 and 2 have the same pattern or not?"

$\mathrm{SPS}_{2} 1$ : "Same ma'am."

$\mathrm{PWPS}_{2} 1$ : "Why is it the same? Isn't the shape different?"

$\mathrm{SPS}_{2} 1$ : "The shape is different but still includes in the same pattern, 1-4-1."

$\mathrm{PWPS}_{2} 1$ : "How do we know whether the pattern is the same or not?"

$\mathrm{SPS}_{2} 1$ : "The pattern can be seen from the number of combined sides in the nets. For example, as in Figure 1 , first, there is only one side, then it is a combination of four sides, then there is one more side so that the pattern is named 1-4-1." 
The written test results also showed that subject 2 was able to imagine the appearance of objects from different perspectives in drawing the arrangement of the cube in two-dimensional front and side shapes shown in Figure 2.b, determine the number of unit cubes contained in the structure shown in Figure 2. c. However, the subject was not able to determine the surface area of the shape to be precisely painted, as shown in Figure 2.d.

The error made by subject 2 in Figure 2.d was in determining the number of squares contained on the invisible side of the solid geometry because the subject was not careful in counting the square, the subject assumed that the number of square units on that side was the same as the number of unit cubes. This is in line with the following interview excerpt.

$\mathrm{PWPS}_{2} 3$ : "If the number of the square that appears on the surface of the solid geometry is most likely correctly calculated. What about the invisible side, how can you know that there are 45 of them?"

$\mathrm{SPS}_{2} 3$ : "We can count how many cubes there are on the invisible side."

PWPS $_{2} 3$ : "It means that the number of cubes on that side determines the number of squares on that side, is that right?"

$\mathrm{SPS}_{2} 3$ : Yes ma'am."

$\mathrm{PWPS}_{2} 3$ : "So, the surface area to be painted is $75+45=120$ square, isn't it?

$\mathrm{SPS}_{2} 3$ : "Yes, it is ma'am."

Thus, it can be concluded that subject 2 answered three out of the four questions correctly. This is shown from the subject's ability to draw different cube nets and determine the relation of the points on the seven-opposite side, draw the arrangement of cubes in two-dimensional shapes from front and side, determine the number of unit cubes contained in a given solid geometry. Still, the subject was not able to determine the number of square units that fulfilled the given surface.

\subsection{Subject 3's Spatial Reasoning Ability}

The spatial reasoning abilities of subject 3 can be seen from the subject's answers in Figure 2.

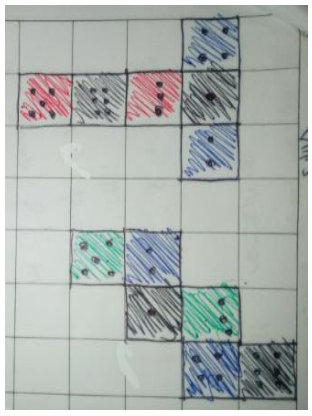

(a)

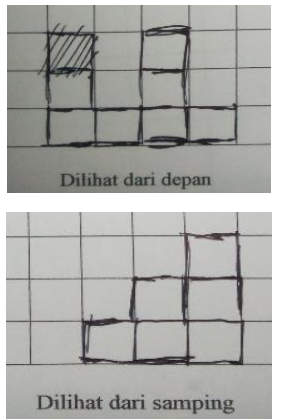

(b)

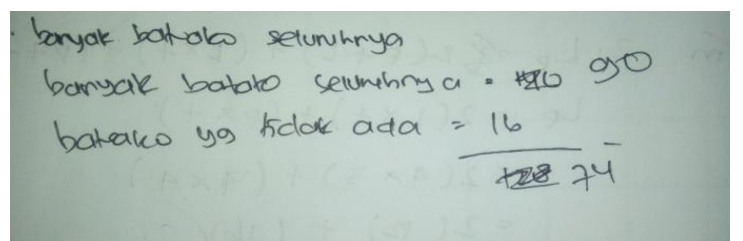

(c)

Figure 5. Subject 3's Answer to the Problem of Spatial Reasoning Abilities

It can be seen in Figure 5 that the subject was able to draw two different cube nets but was not able to determine the relation of points on the totalling seven-opposite sides as the rules on the dice as shown in Figure 5.a. Subject 3 was also able to orientate the arrangement of the squares from different perspectives in accurately drawing the arrangement of squares that appeared from the front and sides as shown in Figure 5.b. However, subject 3 was not able to visualize the object in mind to precisely count the number of concrete blocks in the solid geometry as seen in Figure 5.c. The subject was not able to visualize the unit cube that was not visible. This is consistent with the following interview excerpt.

PW $\mathrm{PS}_{3} 3$ : "How did you find the numbers of concrete bricks in the solid geometry are 90 pieces?"

$\mathrm{SPS}_{3} 3$ : "I estimated the number, actually I was confused on how to count it since there were too many bricklayers and the shape was irregular"

PW PS 33 : "Can you explain how you estimated it?"

$\mathrm{SPS}_{3} 3$ : "If we arranged the bricks to fulfil the solid geometry, so it will look like a cube. Because there were 45 pieces appeared in the picture, so I estimated that if the solid geometry was like a cube then there were altogether $2 \times 45=90$ pieces and there were 16 bricks that were missing from the solid geometry."

$\mathrm{PW} \mathrm{PS}_{3} 3$ : "Where did the 16 come from? Maybe there is an idea you want to convey"

$\mathrm{SPS}_{3} 3$ : "I just guessed the number, ma'am."

PW PS 3 : "So you didn't exactly count then?"

$\mathrm{SPS}_{3} 3$ : "Yes ma'am, actually I didn't understand how to count it"

The written test results showed that subject 3 only answered three out of the given four questions. The subject did not answer question number 4 . After all, the subject was not able to determine the given surface area because the subject tended to use a formula to solve Problem 3.b. In contrast, the ability that should be used in solving this problem was the spatial reasoning abilities. This is related to the following interview excerpt.

$\mathrm{PW} \mathrm{PS}_{3} 3$ : "Do you understand the question?"

$\mathrm{SPS}_{3} 3$ : "Understood, ma'am, I was just confused about how to count it."

$\mathrm{PW} \mathrm{PS}_{3} 3$ : "What's confused?"

$\mathrm{SPS}_{3} 3$ : "I didn't know what the formula was"

$\mathrm{PW} \mathrm{PS}_{3} 3$ : "What kind of formula do you mean?"

$\mathrm{SPS}_{3} 3$ : "Formula for surface area ma'am, usually there is a formula. Yet because the form was not familiar, I did not know the formula." 
Thus, it can be concluded that subject 3 only fulfilled two out of four questions given, and one problem was only partially fulfilled. The student could manipulate objects in mind to draw two different patterns of cube nets, but was unable to determine the relationship of facing sides. She/he was able to imagine the appearance of objects from different perspectives in drawing the arrangement of squares that were seen from the front and side.

\subsection{Subject 4's Spatial Reasoning Ability}

The spatial reasoning ability of subject 4 can be seen from the subject's answers in Figure 6.

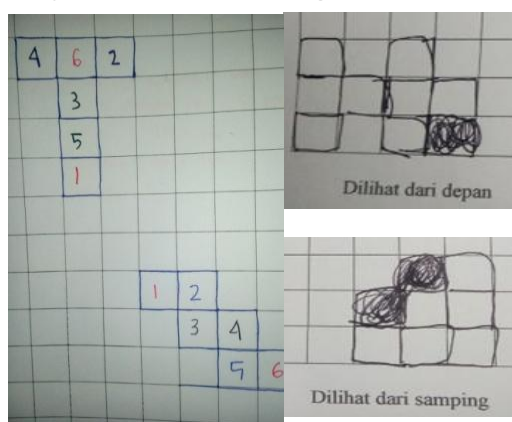

(a)

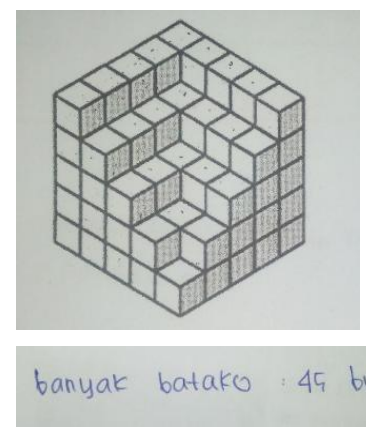

(c)
Figure 6. Subject 4's Answers to the Problem of Spatial Reasoning Abilities

In Figure 6, it can be seen that subject 4 drew two different cube nets with 1-4-1 and 2-2-2 patterns, but the points drawn on the opposite sides did not comply with the rules on the dice. Mistakes made by subjects in determining relations in the webs were not only because they were not able to determine the facing sides but also did not know how to arrange the totalling seven-points on a dice. It showed that subject 4 was only able to draw two cube nets with different patterns.

In Figure 6.b, subject 4 drew a box arrangement that looks from the front in the shape of a square in the order of the numbers 2-1-2-1 and front view 1-2-3. Based on the answers, it can be seen that from both perspectives, the subject only made mistakes in drawing what appears from the front, while the side view was correct. The drawing of the box shown from the front was the wrong answer; it should be square in the order of the number of 2-1-3-1 boxes. The error was made because the subject mistakenly assumed the front view of the boxes arrangement. The subject described the arrangement of the boxes which appeared from above. Besides, the number of squares drawn on the top view was also wrong because it should be in the form of 2-2-3-2. Thus, it can be concluded that subject 4 was only capable of spatial orientation of an object that appears from the side only.

In Figure 6.c, subject 4 wrote that the number of concrete blocks found in the solid geometry was 45 . The subject gave the following explanation in the interview.

PWPS $_{4} 3$ : "Do you understand the command in this question?" $\mathrm{SPS}_{4} 3$ : "Understand ma'am."

PWPS 4 3: "Can you explain a little?"

$\mathrm{SPS}_{4} 3$ : "We were asked to count the number of bricks available on the solid geometry"

PWPS 4 3:"How did you count it?"

$\mathrm{SPS}_{4} 3$ : "I counted them one by one; there were 45 of them."
PWPS 4 : "How did you get this amount?"

$\mathrm{SPS}_{4} 3$ : "I counted manually one by one."

PWPS $_{4} 3$ : "Did you think that the shape was only filled with concrete blocks as seen in the picture or maybe there were also other blocks underneath?"

$\mathrm{SPS}_{4} 3$ : "I thought they were just everything shown in the picture. I didn't think about that when I answered. I thought that what counted was everything given in the picture."

PWPS $_{4} 3$ : "If I ask you to recalculate the number of bricks in the solid geometry, what would be the amount? Please try to look again at the picture."

$\mathrm{SPS}_{4} 3$ : "around 90."

PWPS 4 3: "Why do you use estimation?

$\mathrm{SPS}_{4} 3$ : "I have repeatedly counted different amounts, ma'am. Maybe there was something missed when it was counted."

PWPS $_{4} 3$ : "How did you calculate it? Could you explain it to me?"

$\mathrm{SPS}_{4} 3$ : "I counted from the left side one by one, then continued to the next layer. Well, on the inside, I was wrong, apparently because it was difficult to imagine how many blocks were not seen."

In the interview excerpt, it can be seen that the subject misunderstood the given figure. Subjects only counted the seen bricks in the picture and overlooked the dimensions. After being explained, the subject recalculated the number of bricks manually, but the subject still obtained the wrong answer. This showed that the subject had not been able to do the visualization in problem-solving correctly.

In written answer subject 4 only answered three out of the four questions since the subject did not understand how to determine the surface area of a solid geometry. This is in line with the following interview excerpt.

PWPS $_{4} 3$ : "Did you understand the question about?"

$\mathrm{SPS}_{4} 3$ : "Understood, ma'am, I was just confused how to count it"

PW PS43: "What's confused?"

$\mathrm{SPS}_{4} 3$ : "I didn't know the formula."

PW PS 43 : "Do you know how to calculate the surface area of the cube?"

$\mathrm{SPS}_{4} 3$ : "I forget ma'am, when I was learning in Year 7 also did not understand the topic"

$\mathrm{PW} \mathrm{PS}_{4} 3$ : "If I ask you to calculate the surface area of this classroom, do you know which part we are going to count?"

$\mathrm{SPS}_{4} 3$ : "Don't know ma'am."

In the interview excerpt, it can be seen that subject 4 did not understand the concept of the surface area of a cube, so she/he would not be able to determine the given surface area as well. This means that subject 4 did not have reasoning abilities in determining the given surface area.

Thus, it can be concluded that subject 4 was only capable of answering two out of four problems in which the two answered questions could not be completely fulfilled. The subject was only able to manipulate objects in mind in painting two different cube net patterns but was not able to determine the relations of the opposite sides.

The spatial reasoning ability of subjects $1,2,3$ and 4 through the ELPSA framework are presented in Table 2. 
Table 1. Spatial Reasoning Capability through the ELPSA framework

\begin{tabular}{|c|c|c|c|c|}
\hline \multirow{2}{*}{ Code } & \multicolumn{4}{|c|}{ Question Number } \\
\hline & 1 (VZ-1) & 2 (OR-1) & 3.a (VZ-2) & 3.b (VZ-3) \\
\hline $\mathrm{S}_{1}$ & Partially Fulfilled & Fulfilled & Fulfilled & Partially Fulfilled \\
\hline $\mathrm{S}_{2}$ & Fulfilled & Fulfilled & Fulfilled & Fulfilled \\
\hline $\mathrm{S}_{3}$ & Fulfilled & Fulfilled & Unfulfilled & Unfulfilled \\
\hline $\mathrm{S}_{4}$ & Partially Fulfilled & Unfulfilled & Unfulfilled & Unfulfilled \\
\hline
\end{tabular}

Based on the table, it can be concluded that two out of four subjects were able to manipulate objects in their mind to change D-3 objects into D-2 and determine the relations of facing side according to the rules on the dice. Two out of four subjects were able to imagine the appearance of objects from different perspectives and visualise the number of unit cubes found in the figure. One out of four subjects was only able to manipulate objects in mind to change D-3 objects into D-2 but unable to determine their relationships. In addition, one out of four subjects was able to imagine the appearance of objects from various perspectives to help to determine the surface area of the solid geometry, while did not apply the given size.

The spatial reasoning indicators for Problem 1 can be reached by three out of four subjects to draw two different cube net patterns, while the other subject was only able to draw two cube nets with the same pattern. Related to the visualisation ability in determining the position of points on the facing sides by the rules on the dice, there were 3 out of 4 subjects that met the indicators. In contrast, one other subject was not able to visualise the position of the facing sides precisely. Thus, it can be concluded that the ability of spatial reasoning in terms of visualisation aspects to manipulate objects in mind to change the D-3 object into D-2 and determine the relations of facing sides following the rules on the dice was only completed by two out of four subjects.

The students' spatial reasoning indicators for question number 2 was fulfilled by three out of four subjects in drawing the arrangement of boxes in a warehouse that appeared from the front and sides. In contrast, the other subject only painted the exact arrangement of the cubes that appeared from the side. In drawing the arrangement of bright colours objects, the students were not only able to draw objects from the front and sides but also from above (Fadilah \& Afifah, 2014; Fathoni, 2013; Nofianti., Sugiarti \& Susanto, 2015). However, some students had difficulty in orienting a composition of faded colour objects (Fadilah \& Afifah, 2014). Based on these findings, it can be concluded that the colours in the arrangement of objects did not affect the abilities of spatial reasoning in terms of spatial orientation aspects.

Students' mathematical ability did not influence students' spatial orientation ability. There were not only students who had moderate and low mathematical abilities who had difficulty in spatial orientation to imagine objects from different perspectives but also students with high mathematical abilities (Febriana, 2015). However, students at the secondary school level should be able to understand spatial. Students at this level were at the stage of projective thinking (Francisco), where the students were able to understand changes in three-dimensional objects. Changes in three-dimensional objects, for instance, seeing changes in the object after rotation and how an object is seen from a certain point of view (Mohler, 1980).
For question number 3.a, there were two out of four students who were able to count the number of concrete blocks in the given solid geometry. However, the two subjects counted the number of bricks in different ways. Subject 1 counted the number of cubes by grouping the same number of cubes, while subject 2 counted them manually. The calculation by both subjects applied visualisation abilities because of the process of manipulation of objects in the mind when imagining the number of bricks that were not visible from the given picture.

Whereas the other two subjects who also had the wrong answers made different mistakes. One of them was unable to solve the problem since she/he thought that she/he had to always use formula when working on the problem. This condition happened because students were accustomed to solving mathematical problems with formulas, while the formulas that had been learned were only used to calculate the area or volume of a cube and were not like the given problem. The other subject's problem was to count the total number of bricks in the given solid geometry because the subject was not able to imagine the number of bricks that were not visible in the image.

The visualisation ability of students in calculating the number of bricks on a given solid geometry should help students in understanding the concept of volume. There was not only in the perfect solid geometry but also the imperfect one. Based on the description of the difficulties in visualising, students were more likely to understand procedural rather than conceptual.

Visualisation aspects of spatial reasoning were also measured through the ability to determine the surface area of the cube. However, the ability was not fulfilled by any subject. One subject was able to count the number of squares that fill the surface but did not calculate the surface area by using the given brick size.

In term of mastering the visualisation ability in this problem, the subject had been able to do the visualisation, but unable to associate the ability to determine the surface area. The condition occured because during the implementation of ELPSA framework, the teacher did not emphasise the concept of surface area, which starts from identifying the number of square units in the solid geometry, so students did not tend to memorise the formula for perfect solid geometry. The lack of this concept understanding caused students often unable to solve problems related to surface area and volume (Sumadiasa, 2014).

\section{CONCLUSION}

Based on the results and discussion of students' spatial reasoning abilities through the ELPSA framework, it can be concluded that most students mastered the spatial reasoning for the indicators of visualisation and spatial orientation. The students' spatial reasoning in terms of a visualisation in manipulating objects in mind to draw the changes in D-3 objects into D-2, and determine the relations of facing sides according to the rules on the dice was better than counting the number of unit cubes and the number of square units covering the surface of imperfect cube. The lack of students' spatial reasoning ability in calculating the number of square units covering the plane will lead to students' difficulty in solving problems related to the surface. Students' spatial reasoning abilities concerning spatial orientation was mastered by three out of four subjects in drawing the appearance of objects from various perspectives, both front and side. The ELPSA learning 
framework can be applied as one of the learning approaches to develop students' spatial reasoning abilities. The increase in students' spatial reasoning abilities can help students solve geometry problems related to imperfect solid geometry.

\section{REFERENCES}

Clements, D. H., \& Battista, M. (1992). Geometry and spatial reasoning. In D. A. Grouws (Ed.), Handbook of research on mathematics teaching and learning. New York: Macmillan.

Fadilah, E.N., \& Afifah, D.S.N. (2014). Kecerdasan visual-spasial siswa smp dalam memahami bangun ruang ditinjau dari perbedaan kemampuan matematika. Jurnal Pendidikan Matematika STKIP PGRI Sidoarj, 2(2), 151-158.

Fathoni, L. (2013). Profil kecerdasan visual-spasial siswa dalam memahami gambar bangun ruang yang tersusun dari beberapa bangun kubus. Gramatika, 3(2), 155-161.

Febriana, E. (2015). Profil kemampuan spasial siswa Sekolah Menengah Pertama (SMP) dalam menyelesaikan masalah geometri dimensi tiga ditinjau dari kemampuan matematika. Jurnal Elemen, 1(1), 13-23.

Gutierrez, A. (1994). Visualization in 3-dimensional geometry: In search of a framework. Institution Valenciana de Estudios e Investigation, (1) 1-17

Hegarty, M., \& Waller, D. (2004). A dissociation between mental rotation and perspective-taking spatial abilities. Intelligence, 32(2), 175-191. https://doi.org/10.1016/j.intell.2003.12.001

Lowrie, T., \& Patahuddin, S. M. (2015). ELPSA-Kerangka Kerja untuk Merancang Pembelajaran Matematika. Jurnal Didaktis Matematika, 2(1), 94-108.

Mohler, J. L. (1980). A Review of Spatial Ability Research, 19-30.

NCTM. (2000). Principles and Standards for School Mathematics. School Science and Mathematics. https://doi.org/10.1111/j.1949-8594.2001.tb17957.x

OLKUN, S. (2003). Making connections improving spatial abilities with engineering drawing activities. International Journal for Mathematics Teaching and Learning, (April), 1-10. https://doi.org/10.1501/0003624

Riznani., Halim., \& M. (2016). Dampak Penggunaan Model Quantum Teaching Tipe Vak (Visual, Auditori, Kinestetik) Terhadap Retensi Mengingat Konsep Fisika Siswa Kelas VIII SMPN 6 Banda Aceh, 1(4), 277-283.

Sumadiasa, I.G.(2014). Analisis kesalahan siswa kelas VIII SMP Negeri 5 Dolo dalam menyelesaikan soal luas permukaan dan volume limas. Aksioma: Jurnal pendidikan Matematika, 3(2), 197-208.

Sumarni, \& Prayitno, A. T. (2016). Kemampuan Visual-Spatial Thinking Dalam Geometri Ruang Mahasiswa. Jurnal Imiah Pendidikan Matematika, 2(2), 81-100.

Yilmaz, B. (2009). On the development and measurement of spatial ability. International Electronic Journal of Elementary Education, 1(2), 1-14. Retrieved from www.iejee.com 